\title{
Spinal Cord Disorder
}

National Cancer Institute

\section{Source}

National Cancer Institute. Spinal Cord Disorder. NCI Thesaurus. Code C97110.

A non neoplastic or neoplastic disorder that affects the spinal cord. 